\title{
LA NECESARIA REFORMA DEL MODELO DE REPRESENTACIÓN ANTE LA PROBLEMÁTICA DE LA ESPAÑA VACIADA
}

\author{
Gabriel Moreno González \\ Profesor de Derecho Constitucional, \\ Universidad de Extremadura
}

Cómo citar este artículo / Citation: Moreno González, G. (2021). La necesaria reforma del modelo de representación ante la problemática de la España vaciada.

Palacios Romeo, F. y Cebrián Zazurca, E. (coords.) Elección y representación: una conjunción compleja. Perspectivas y problemas de los regímenes electorales en España, Colección Obras colectivas, Fundación Manuel Giménez Abad, Zaragoza.

DOI: https://doi.org/10.47919/FMGA.OC21.0303

SUMARIO: I. LA ESPAÑA RURAL Y VACIADA: PROBLEMA DE INTEGRACIÓN CONSTITUCIONAL - II. LA SOBRREREPRESENTACIÓN ELECTORAL DE LA ESPAÑA RURAL Y LA EQUIDAD TERRITORIAL - III. ¿HACIA UNA CORRECCIÓN REPRESENTATIVA DEL SISTEMA DE PARTIDOS? - IV. CONSIDERACIONES FINALES

\section{LA ESPAÑA RURAL Y VACIADA: PROBLEMA DE INTEGRACIÓN CONSTITUCIONAL}

Junto a la problemática de la reforma constitucional, la cuestión territorial se mantiene como uno de los tradicionales, históricos y constantes focos de tensión jurídico-políticos que se desprenden directamente de nuestras constituciones, la actual incluida. La apertura inicial de la descentralización política se ha ido cerrando durante estas cuatro décadas gracias a los renovados consensos de generalización del sistema que se han sucedido, la voluntad política compleja de un modelo ya nítidamente compuesto y la labor 
jurisprudencial del Tribunal Constitucional, a veces objeto de excesivas y desproporcionadas críticas. Sin embargo, y aunque las Comunidades Autónomas hayan alcanzado niveles razonables de equiparación entre ellas y de seguridad jurídica en torno a su autonomía, el modelo sigue adoleciendo de una falta de completud derivada de la indefinición constituyente originaria y de sus fallas principales. De entre estas destacan, principalmente y con relevancia constitucional, tres: la procelosa complejidad de la distribución de competencias y su altísima conflictividad, la nula participación de las CC.AA. en la reforma constitucional más allá de su tenue iniciativa, y la poca presencia de las mismas en la formulación normativa de la voluntad estatal. Si bien las tres son síntomas de la necesidad imperiosa de adecuar nuestro marco constitucional a las demandas de un sistema ya maduro, son las dos últimas las que mejor manifiestan el camino que nos falta por recorrer para conseguir un auténtico y consolidado sistema federal, al margen de que algunas de sus múltiples caras ya puedan proyectarse sobre el modelo presente ${ }^{1}$. De tales "defectos", si pudieran calificarse como tales, la mejor doctrina española ya ha dicho suficiente y bastante, y no es lugar este, ni la intención, repetir lo que otros han escrito con más detalle y, seguramente, mayor acierto ${ }^{2}$.

Ahora bien, sí hay que destacar un fenómeno ciertamente curioso, y es el que se refiere a la práctica identificación de las causas y consecuencias de aquellos síntomas, en tales análisis, con los problemas políticos inferidos del encaje territorial de la diversidad y pluralidad nacionales. La "cuestión territorial" se ha venido así a confundir con la "cuestión catalana", o vasca, monopolizando el debate de la reforma constitucional en dicho ámbito y de manera notoria, además, tras el inicio del llamado procés y sus alteraciones políticas en el tablero español. Que también es precisa una mejor adecuación de nuestro sistema institucional a la plural realidad identitaria y nacional española, me parece evidente y así lo he sostenido en otra sede ${ }^{3}$. Los arreglos constitucionales que para tal fin se diseñen no deben, además, circunscribirse únicamente a los planos jurídico, competencial o procedimental, pues parece

\footnotetext{
${ }^{1}$ Blanco Valdés, R., Los rostros del federalismo, Madrid, Alianza, 2012.

2 Por todos, Solozábal, J. J. Edit. La reforma federal: España y sus siete espejos, Madrid, Biblioteca Nueva, 2014; García Roca, J. Edit, Pautas para una reforma constitucional: informe para el debate, Pamplona, Thomson Reuters Aranzadi, 2014; Muñoz Machado, S., Informe sobre España: repensar el Estado o destruirlo, Barcelona, Crítica, 2012.

${ }_{3}^{3}$ Moreno González, G., "España, cuestión de integración constitucional", El Cronista del Estado Social y Democrático de Derecho, oㅡ 80, 2019, pp. 68-75.
} 
claro que estamos también ante problemas de índole simbólico y de adscripción identitaria que necesitan de una mayor integración en el sentido dado en su día por Rudolf Smend ${ }^{4}$. Sobre la oportunidad y la posibilidad de que los impulsos centrífugos sean finalmente canalizados por un marco constitucional renovado aún no podemos pronunciarnos, máxime cuando estamos insertos de lleno en múltiples crisis que ocultan, por su relevancia, la relacionada con aquellos impulsos.

Sin embargo, lo nacional no agota lo territorial. España tiene un segundo problema al respecto, y para muchos, como el que escribe estas líneas, más acuciante, intenso y determinante. Me refiero a la galopante despoblación de una buena parte del territorio nacional y la correlativa hiperconcentración urbana que se da en zonas muy reducidas del mismo, problemática tan gráficamente bautizada bajo la exitosa adjetivación de la "España vacía" ${ }^{5}$. Aun así, preferimos aquí utilizar la ahora más común de "España vaciada", pues el participio hace hincapié en la acción constante, previa y presente, que ha provocado ese vaciamiento y de la que pueden colegirse sus causas y sus principales agentes promotores. Y, con ello, tampoco esta denominación sería del todo correcta, pues siempre hay que recalcar que, en esa otra España, la olvidada, la rural, la de los pueblos y pequeñas ciudades, vive gente, poca sí, pero teóricamente igual en derechos que la que habita concentrada. Sea como sea, la adjetivación del nombre del propio país ha ayudado a poner de manifiesto y a colocar en la agenda mediática, bajo un término más o menos unívoco y fácilmente identificable, un problema integral y transversal que afecta de manera intensa a su misma cohesión política, social y económica. Primero, porque no podemos seguir permitiendo que una parte nada desdeñable de la población, si bien no la mayoritaria, siga estando en una situación de subordinación y menor disfrute de sus derechos fundamentales, y no solo los sociales, únicamente por causa del lugar en el que viven. Segundo, porque los grandes desafíos del presente, como el cambio climático, la contaminación o la atomización social de un individualismo compulsivo, se incrementan si se continúa abandonando las formas de vida tradicionales, rurales, respetuosas y armoniosas con el medio ambiente y aún revestidas de aquella

\footnotetext{
${ }^{4}$ Smend, R., Constitución y Derecho Constitucional, Madrid, Centro de Estudios Políticos y Constitucionales, 1985.

${ }^{5}$ Del Molino, S., La España vacía: viaje por un país que nunca fue, Barcelona, Turner, 2016.
} 
Gemeinschaft de las que nos hablaba Ferdinand Tönnies, ${ }^{6}$ que constituyen un baluarte, quizá el último, frente a las "nuevas" modalidades deshumanizadas de existencia y a la preocupante desconexión de la persona con la naturaleza a la que pertenece ${ }^{7}$.

¿La despoblación y el abandono del medio rural es un fenómeno singular de España? Ni mucho menos. Ambos procesos son correlativos a la construcción de la sociedad capitalista contemporánea, cuyo sistema económico precisa de altos niveles de concentración en todos los ámbitos, incluido el territorial. La gran ciudad como fenómeno contemporáneo es consustancial al determinado conjunto de relaciones económicas que nos preside desde que se consolidara el paradigma de la contemporaneidad capitalista y urbana. No es de extrañar que Polanyi ${ }^{8}$, cuando analiza la irrupción de dicho paradigma, lo asocie siempre al surgimiento de las megalópolis europeas y a la consiguiente pérdida de los vínculos primarios (al decir de Fromm) que conllevó aquella gran transformación industrial y económica ${ }^{9}$. Empero, la despoblación rural en España, aunque se deba también y principalmente a tales causas, está singularmente intensificada por una secular desvertebración del territorio nacional, por un proceso rapidísimo y tardío de "modernización" y por una hiperconcentración destacada que no tiene equivalencia en el resto de Europa. Por ejemplo, en España la "densidad habitada", concepto mucho más clarificador para analizar la cuestión demográfica en un país, es la más alta de Europa. La población apenas vive en el 13\% del territorio, y en ese espacio la densidad efectiva es de 737 personas por $\mathrm{km}^{2}$. Si contáramos todo el país, no sólo las zonas más habitadas, la densidad se reduciría a... ¡93 personas $/ \mathrm{km}^{2}$ !, cuando la media de la Unión Europea en este último parámetro está en 177 (Alemania, con 233). Si nos trasladamos a provincias como Soria o Palencia, aquella cifra se reduce hasta niveles árticos. La despoblación se ceba especialmente con las dos Castillas y en todo el oeste, con niveles equivalentes a "desierto demográfico" en la frontera hispanolusa (la Raya), y la denominada Celtiberia (Sistema Ibérico). A fortiori, en Europa existen 33 áreas

\footnotetext{
${ }^{6}$ He tenido la oportunidad de abordar con detenimiento tales problemáticas en mi libro La democracia humanista, Sevilla, Athenaica, 2020.

${ }_{7}$ Quizá uno de los autores que ahora mejor manifiestan en su obra dicha desconexión o deshumanización sea Byung-Chul Han: In toto, La sociedad del cansancio, Barcelona, Herder, 2017; La sociedad de la transparencia, Barcelona, Herder, 2013. En España, quien ha abordado en profundidad y desde el inicio este fenómeno es el profesor Jorge Riechmann.

${ }^{8}$ Polanyi, K., La gran transformación, Madrid, Fondo de Cultura Económica de España, 2011.

${ }^{9}$ Fromm, E., El miedo a la libertad, Paidós Ibérica, 2018.
} 
en las que hay más de 40.000 habitantes por $\mathrm{km}^{2}$, pero 20 de ellas se sitúan en España. En las dos últimas décadas, y de acuerdo con el Instituto Valenciano de Investigaciones Económicas, siguiendo los datos del INE, el 63\% de los municipios españoles y 13 provincias han perdido habitantes, a pesar de que en su conjunto el país no ha dejado de crecer demográficamente ${ }^{10}$. El ejemplo paradigmático de la hiperconcentración urbana correlativa a la despoblación rural lo constituye la ciudad de Madrid, que ha crecido un 73\% desde 1975. Estos datos demuestran tanto la singularidad española en la intensidad de la despoblación rural como la pertinencia de reivindicar un concepto, y una problemática, también singulares.

¿Cómo afecta esta realidad a la democracia constitucional? Al igual que tenemos una parte de la población (nacionalismos centrífugos) desafecta con el proyecto político común y lo solemos considerar como un problema político susceptible de ser solucionado institucional y jurídicamente, deberíamos tratar también la cuestión demográfica como una ausencia clamorosa de integración constitucional que afecta a un sector de la población y, lo que no es menos importante, a la mayor parte de nuestro territorio. A la población porque, ahora tamizada bajo el enfoque constitucional como ciudadanía, no disfruta de un nivel equivalente de prestaciones y derechos y, en tanto tal, no accede en pie de igualdad con la población urbana a las posibilidades que otorga el Estado social y democrático de Derecho. A los territorios porque, muy vinculada a la anterior afectación, su desvertebración e intensa despoblación, cuyas causas vienen determinadas por decisiones económicas y políticas, suponen la quiebra del principio de solidaridad interterritorial que la Constitución establece y que se ampara, al tiempo, en el propio Estado social. El contenido esencial de la adjetivación de nuestro Estado en el primer artículo de la norma fundamental, como magistralmente ha argumentado el maestro Carlos de Cabo ${ }^{11}$, consiste en la pervivencia, mantenimiento e incluso impulso del principio interventor de lo estatal sobre lo económico y lo social con posibles fines transformadores y, siempre, con objetivos de una mayor justicia y equidad. $Y$ ello se traduce, además, en una especial preocupación constitucional por la solidaridad interterritorial, consciente el constituyente de las graves y profundas

\footnotetext{
${ }^{10}$ Todos los datos indicados pueden consultarse, más allá de las fuentes oficiales del INE, en: https://www.epdata.es/datos/despoblacion-espana-datos-estadisticas/282 [Última consulta: 4 de noviembre de 2020].

${ }^{11}$ Cabo Martín, C., Teoría constitucional de la solidaridad, Barcelona, Marcial Pons, 2006.
} 
disparidades económicas que ya existían en la España de la Transición como consecuencia del disparatado proceso de "modernización" económica protagonizado por el "desarrollismo" franquista. En palabras del propio De Cabo, "la conciencia de que el desarrollo desigual es un dato estructural básico de la formación social española está reiteradamente presente en la Constitución y aparece con toda evidencia que es la causa primera de la exigencia de este tipo de solidaridad"12. Esta vinculación del principio de solidaridad inter-autonómica con el contenido normativo del Estado social ${ }^{13}$ apenas ha sido explorada por la doctrina, no así la crítica que viene a representar el propio autor, lo cual devela también la falta de compromiso de parte de la dogmática por la normatividad real y plena de todos los preceptos y previsiones constitucionales. Una vinculación que no es producto de tortuosos silogismos académicos o de pruritos de abstracta especulación, pues viene expresamente recogida en el texto constitucional y en uno de sus (tantos) olvidados artículos. Vale la pena rescatar el tenor del 138 (cursiva nuestra): "El Estado garantiza la realización efectiva del principio de solidaridad consagrado en el artículo 2 de la Constitución, velando por el establecimiento de un equilibrio económico, adecuado y justo entre las diversas partes del territorio español, y atendiendo en particular a las circunstancias del hecho insular". Al que hay que añadir las previsiones del artículo 158, tanto en sus referencias a la necesidad de garantizar "un nivel mínimo en la prestación de los servicios públicos fundamentales en todo el territorio español", como a la finalidad de "corregir los desequilibrios económicos interterritoriales y hacer efectivo el principio de solidaridad". Y, como quiera que esa pretensión más interventora en la economía del Estado social viene acompañada y amparada por un Estado democrático y de Derecho en el que se garantizan los derechos fundamentales, incluidos algunos de los sociales, la Constitución también se preocupa del igual disfrute de los mismos sin distinción del lugar de nacimiento, estableciendo que "todos los españoles tienen los mismos derechos y obligaciones en cualquier parte del territorio del Estado" (art. 139) y habilitando al Estado central, como máximo defensor del interés general, a regular "las condiciones básicas que garanticen la igualdad de todos los españoles en el ejercicio de los derechos y en el cumplimiento de los deberes constitucionales" (art. 149.1).

\footnotetext{
12 Ibid., p. 93.

${ }^{13}$ lbid., pp. 95-97.
} 
El abandono del medio rural, de la mayor parte de nuestro territorio nacional y, por consiguiente, de las gentes y pueblos que en él habitan, ¿supone un atentado a estas previsiones y mandatos constitucionales? La respuesta es claramente afirmativa si tenemos en cuenta que las causas del fenómeno no son naturales, necesarias, sino contingentes y debidas al diseño consciente de una serie de condicionantes que lo impulsan, favorecen y aseguran. El proceso de hiperconcentración urbana no ha sido corregido por el sistema autonómico ni por el Estado (compuesto), y va de la mano de la desintegración y difuminación de los mecanismos de intervención económica del Estado social $^{14}$. La distribución de la riqueza se ha dejado fundamentalmente a un sector privado que, movido por sus intereses particulares, no se preocupa por corregir desequilibrios territoriales que poco le importan y que en mucho le benefician al abaratarse los costes fijos de la producción de bienes y servicios. Menos le interesa, por supuesto, la conservación y preservación de las formas tradicionales de vida, incompatibles con el individualismo posesivo y el consumismo desaforado que caracteriza a las megalópolis actuales. El Estado, al quedarse inerme por haber abandonado sus instrumentos de intervención y transformación socioeconómicos (a veces de manera deliberada, otras por clara contemporización), es incapaz también de cumplir y hacer cumplir con los mandatos de solidaridad derivados de su adjetivación social, perdiéndose con ello la fuerza normativa de un conjunto de preceptos constitucionales cuya ausencia actual de virtualidad jurídica tendría que hacernos repensar la propia supremacía de la Constitución y, por tanto, la pervivencia misma de la soberanía popular en que se funda ${ }^{15}$.

En cuanto a los niveles de integración simbólica y afectiva de esa población rural que ve cómo poco a poco el Estado y sus servicios se va retirando del territorio, cómo con el paso acelerado del tiempo los pueblos van degradándose y las comarcas quedándose sin vecinos, ¿creemos de verdad que sus habitantes pueden fungir como ciudadanos conscientes de serlos e integrados en una comunidad política mayor de la que se sienten partícipes en igualdad de condiciones? Es extensa ya la literatura que ha estudiado la desafección de los habitantes del mundo rural, que puede ser

\footnotetext{
${ }^{14}$ Moreno González, G., "El cierre de la constitución económica española: de la apertura de posibilidades al monismo de obligaciones", lus Fugit: Revista Interdisciplinar de Estudios Histórico-Jurídicos, № 20, 2017, pp. 117-156.

${ }^{15}$ De Cabo Martín, C., Pensamiento crítico, constitucionalismo crítico, Madrid, Trotta, 2014.
} 
preocupantemente instrumentalizada por pretendidas soluciones populistas y políticamente extremas. El problema territorial no es solo, pues, el de las identidades superpuestas e institucionalizadas por nacionalismos centrífugos más o menos desarrollados; es también el del propio territorio abandonado que puede terminar desarticulando la propia idea de ciudadanía en sus habitantes.

\section{LA SOBRERREPRESENTACIÓN ELECTORAL DE LA ESPAÑA RURAL Y LA EQUIDAD TERRITORIAL}

El incremento de las desigualdades territoriales, en contra de lo establecido en la Constitución, tiene como una de sus causas principales la quiebra del Estado social y del principio de solidaridad, como hemos dicho, pero en esta contribución quisiera centrarme en si en esa quiebra (deliberada o no), y en su administración hacia un posible cambio de paradigma, lo rural tiene una voz suficiente en la formación misma de la voluntad política. La cuestión no es baladí, pues al margen de si existe o no actualmente una conciencia ciudadana de la problemática desde y por los territorios afectados, sería clave dilucidar si al menos, si se diera esa conciencia y se articulara políticamente, la misma podría trasladarse al seno de la representación en virtud del principio democrático. ¿Están o podrían estar los intereses de la ciudadanía rural y de las pequeñas y medianas ciudades de la España vaciada debidamente representados en los órganos que elaboran la voluntad político-estatal? Desde luego, si se hace un análisis formal (y formalista) del sistema electoral español no hace falta ser un experto en la materia para percatarse de la sobrerrepresentación de las provincias con baja densidad de población, tanto en el Congreso de los Diputados como en el Senado, con lo que ello conlleva en un sistema parlamentario a la hora de formar también el Gobierno de la Nación. Como ponen de manifiesto, inter alia, Ramón Montero y Fernández Esquer $^{16}$, la decisión constituyente de establecer la provincia como circunscripción electoral y de repartir automáticamente una parte de los escaños entre las mismas sin tener en cuenta la población ("prorrateo desviado", o malapportionment), tuvo una clara intención de moldear desde el

\footnotetext{
${ }^{16}$ Montero, J. R. y Fernández Esquer, C., "Cuatro décadas del sistema electoral español, 19772016", Política y Gobernanza. Revista de Investigaciones y Análisis Político, № 2, 2018, pp. 546.
} 
sistema electoral la posibilidad de condicionar los resultados para imponerles un sesgo mayoritario y conservador que beneficiara a los partidos más consolidados a nivel nacional. Hemos de tener en cuenta que el actual sistema, cuyos elementos clave están establecidos en el artículo $68 \mathrm{CE}$, procede en dichos aspectos del Real Decreto-ley 20/1977, de 18 de marzo, sobre Normas Electorales, que fue un acto normativo unilateral del entonces gobierno Suárez y que buscaba, sin ocultarlo, beneficiar al partido oficialista, la UCD. Como apunta la profesora Soriano Moreno, "es conocido que el sistema se configuró por parte de los miembros del Gobierno con base en las encuestas electorales y de forma que el sistema beneficiara a sus intereses (de ahí el sesgo conservador) y con la apariencia de negociación debida a las consultas realizadas con la oposición"17. En los debates constituyentes al respecto, analizados en detalle por la autora, la izquierda del PCE criticó con dureza la elección de la provincia por sobrerrepresentar las zonas rurales, en la creencia de que en las mismas imperaba aún y con mayor intensidad el famoso y temido "franquismo sociológico", mientras que la derecha del Sr. Fraga Iribarne apostaba más por un modelo mayoritario ${ }^{18}$. Y es que finalmente la delimitación de los rasgos principales o esenciales del sistema, constitucionalizados y petrificados en la Constitución, correspondió a una transacción entre el PSOE y la UCD, que dejó fuera al PCE y a AP, y que convino en la necesidad de garantizar constitucionalmente la representación proporcional, la provincia como circunscripción y un prorrateo mínimo de escaños por criterio territorial ${ }^{19}$. Como es bien sabido, la constitucionalización de estos elementos y la rigidez consiguiente de los mismos en la definición de las líneas maestras del sistema electoral, le ha dotado a este de un claro sesgo mayoritario y conservador que tiende a beneficiar a los partidos nacionales bien asentados en todo el territorio $y$, también, a aquellos que, por su ideario, se concentran en unas pocas circunscripciones, como los nacionalistas o de corte regionalista. En cambio, los máximos perjudicados son los partidos minoritarios con apoyos dispersos y que no consiguen concentrar su potencial de voto ${ }^{20}$. De acuerdo con un reciente y conocido estudio, de 160 países examinados, España se encontraría en el puesto 108 en lo relativo a voto desigual (malapportionment) dada la

\footnotetext{
17 Soriano Moreno, S., "El sistema electoral de las Cortes Generales a través de su proceso de constitucionalización", Teoría y Realidad Constitucional, no 45, 2020, pp. 567-596; pp. 574-575. ${ }^{18}$ Ibid., p. 580.

${ }^{19}$ Montero J. R., y Fernández Esquer, C., op. cit., p. 11.

${ }^{20}$ lbid., pp. 14-19.
} 
profundidad de los sesgos antedichos y el desvío del prorrateo que se produce $^{21}$. Como dice Urdánoz Ganuza ${ }^{22}$, parecía que incluso nos encontráramos con una aporía en el texto constitucional, que proclama la igualdad de voto (68.1 CE) para desmentirlo justo a continuación con la determinación de la provincia como circunscripción provincial (68.2 CE). Siguiendo su gráfica denuncia, "el 68.1 garantiza un derecho que la combinación con el 68.2 impide"23.

En este sentido, el medio rural y, paradójicamente, la llamada "España vaciada", quedan al tiempo sobrerrepresentados dada la elección de la provincia como circunscripción y el prorrateo automático de escaños (actualmente 2, reducible a 1 mediante reforma de la LOREG) que responde al mandato constitucional ya indicado. Como apuntan Samuels y Snyder ${ }^{24}$, la sobrerrepresentación rural es una nota más común de lo que a veces se piensa en el panorama comparado y singularmente en los países anglosajones ${ }^{25}$, como Estados Unidos. Recordemos al respecto la famosa sentencia Baker vs. Carr, de 1962, que estudió directamente este fenómeno a la luz del principio "una persona, un voto". A la sobrerrepresentación hay que añadir, además, el llamado "efecto varianza", que se da en las circunscripciones rurales o con pocos escaños y que dificulta la presentación de candidaturas alternativas a las mayoritarias en las mismas, reduciéndose la competición y agravándose, con ello, los efectos mayoritarios del sistema, más si cabe si a ese efecto en los partidos sumamos el llamado "voto útil" desde los electores.

La sobrerrepresentación electoral del mundo rural, tanto en el Congreso como en el Senado, parece así evidente. ¿Por qué ello no se ha trasladado a una acción política más decidida contra la despoblación y el abandono de las provincias que presentan la crisis demográfica antedicha? Penadés y Pavía apuntan a que a los sesgos mayoritario y conservador hay que añadir en

\footnotetext{
${ }^{21}$ Haití Ong K.-M., Kasuya Y. y Mori K., "Malapportionment and democracy: a curvilinear relationship", Electoral Studies, ํo 49, 2017, p. 373.

${ }_{22}$ Urdánoz Ganuza, J., "¿Una antinomia constitucional? El sufragio (des)igual en la Constitución de 1978", Teoría y Realidad Constitucional, no 45, 2020, pp. 353-378.

${ }^{23} \mathrm{Ibid}, \mathrm{p} .363$.

24 Samuels, D., y Snyder R., "The Value of a Vote: Malapportionment in Comparative Perspective", British Journal of Political Science, № 31, 2001, pp. 651-671; p. 659.

${ }^{25}$ Sobre los famosos "burgos podridos" británicos: Ertman T., "The Great Reform Act of 1832 and british democratization", Comparative Political Studies, ำ 43, 2010.
} 
nuestro sistema electoral uno marcadamente "centralista" ${ }^{26}$, pues son los partidos con una destacada presencia en todo el territorio los que defienden supuestamente posturas más centralistas y menos favorables a la federalización del país, tanto simbólica como materialmente. Esto es así en el caso del Partido Popular, pero habría que presentar serias dudas a la formulación de los autores en lo que respecta al otro gran partido, el PSOE, puesto que oficialmente es partidario de un modelo federal que ahonde en la descentralización política. Y, aun así, tal y como hemos analizado, esa posibilidad de avanzar hacia un modelo federal, o más federal, no debe tampoco vincularse obligatoriamente con una mejor estructuración, demográfica, económica y social, del territorio y sus disparidades, puesto que la laminación de las potencialidades redistributivas del Estado social se da tanto si el modelo fuera más centralizado como descentralizado. Es más, principios asociados al "federalismo fiscal", que implican la competencia en materia impositiva entre entes territoriales, $u$ otros no menos populares últimamente y asociados a una mayor descentralización, como el de "ordinalidad", coadyuvarían aún más a la degradación de la posibilidad redistributiva del Estado. El dumping fiscal como resultado de aquella competencia, y la reducción de la solidaridad interterritorial en tanto corolario de la limitación que conlleva el principio de ordinalidad, terminarían por desactivar los pocos instrumentos de redistribución que aún contamos ${ }^{27}$. Quizá no es tan conocida, al respecto, la predilección en la teoría de las diversas escuelas neoliberales por los marcos políticos descentralizados, ya que en ellos vierten sus deseos de competencia entre unidades políticas y su abierto e indisimulado recelo por el poder político soberano con fuertes capacidades de intervención (jacobinismo) ${ }^{28}$. Es más, algunas de estas dinámicas propiamente neoliberales ya se hacen notar en el funcionamiento del sistema autonómico, que adolece de una mejor armonización fiscal en determinados impuestos ${ }^{29}$ y que está lastrado, en sus mecanismos interventores, por principios como el de

\footnotetext{
${ }^{26}$ Penadés, A., y Pavía J. M., La reforma electoral perfecta, Madrid: Los Libros de la Catarata, 2016, p. 69.

${ }^{27}$ Una crítica al principio de ordinalidad, en De Cabo M., Teoría constitucional de la solidaridad, op. cit., p. 104.

${ }^{28}$ Sobre el particular, Moreno González, G., "La teoría de la Constitución en James Buchanan: hacia un modelo de economía constitucional", Revista de Estudios Políticos, oㅜ 177, 2017, pp. 57-88; pp. 80-81; Buchanan, J. M., Los límites de la libertad. Entre la anarquía y el Leviatán, Madrid, Katz Editores, 2009, p. 155.

${ }_{29}$ Manzano Silva, M. E., Autonomía, coordinación y solidaridad en el régimen común de financiación autonómica, Madrid, Instituto de Estudios Fiscales, 2012.
} 
estabilidad presupuestaria y sostenibilidad financiera, tal y como ha estudiado con detenimiento Guerrero Vázquez ${ }^{30}$. Si relacionamos las posibilidades de solidaridad interterritorial con la defensa del Estado social en sentido fuerte y propio, hemos de relacionar también a aquellos partidos políticos que, o bien son contrarios a dotarlo de tal potencialidad, 0 bien son incapaces, estructuralmente, de hacerlo por aceptar apriorísticamente el marco económico y jurídico preestablecido y condicionado, también, por la Unión Europea y sus elementos estructurantes.

La sobrerrepresentación rural ha de ser entendida y analizada, asimismo, desde el interior de una partidocracia en la que son los partidos, con sus máximos dirigentes al frente y sus estructuras más o menos jerarquizadas, los que trazan las líneas fundamentales de la actuación política. Entre las preferencias de esta la España rural nunca ha figurado hasta la actualidad, cuando se están dando teóricos acercamientos a la problemática desde casi todos los partidos en sus programas electorales ${ }^{31}$. No obstante, la vinculación que el representante pueda tener con sus provincias menos densamente pobladas y en cierta medida, como vemos, sobrerrepresentadas, no tiene por qué trasladarse en una actuación más decidida en cuanto al reto demográfico, por cuanto la disciplina de partido y la jerarquía dimanada de la élite del mismo, con un fuerte sesgo urbano ${ }^{32}$, termina laminando las posibilidades de que autónomamente pueda trasladar a la voluntad estatal soluciones efectivas en la materia.

Por supuesto, las listas electorales, al ser cerradas y bloqueadas en el Congreso, y al venir determinadas por las estructuras internas de los partidos,

${ }^{30}$ Guerrero Vázquez, P., Freno constitucional al endeudamiento y descentralización política, Zaragoza, Fundación Manuel Giménez Abad, 2020.

${ }^{31}$ Podemos dedicó un capítulo completo, llamado Garantías de Justicia Territorial, en el programa de las últimas elecciones generales de 2019, asumiendo el concepto de España vaciada; el PSOE fue más escueto bajo la rúbrica de "Reto demográfico". Por su parte, el Partido Popular abordó a lo largo de todo su programa cuestiones específicas que afectan a la despoblación del mundo rural, sin sumarse al concepto de España vaciada; y Ciudadanos dedicó también un capítulo específico para defender un Pacto de Estado contra la Despoblación, fundamentado sobre todo en políticas favorables al emprendimiento y en rebajas fiscales selectivas.

${ }^{32}$ Así se constata en el análisis empírico del lugar de procedencia, rural o urbano, que realizan Jerez, M., Liz J. J., y Real-Dato, J., "Los diputados en la nueva democracia española, 19772011: pautas de continuidad y de cambio", en Linz, J. J., Obras escogidas, vol. 6, Partidos y élites políticas en España, Madrid, Centro de Estudios Políticos y Constitucionales, 2013; especialmente en pp. 66-69. 
se deben más a los criterios de oportunidad de los mismos y de su dirigencia que a la especial relación con la circunscripción que puedan mostrar los candidatos que se presentan. Las elecciones generales, presididas por un debate nacional y sobre cuestiones que en nada o poco se referencian en el territorio concreto del que parte el representante, terminan siendo plebiscitos sobre los cabezas de partido que arrastran tras de sí a una numerosa y desconocida lista de representantes, tratados numéricamente como apoyos de cara a una posible y siempre deseada mayoría parlamentaria que permita ser opción de gobierno o de influencia en él. Algo que desde luego es ínsito en el Congreso de los Diputados, la cámara con verdadero poder decisorio, pero que también se traslada a los cuatro senadores por provincia que son elegidos en las generales, y que vienen establecidos por los partidos con idéntico criterio a pesar del carácter territorial que la Constitución quería darle a la Cámara (art. 69).

He aquí, al margen de las cuestiones anteriores o, más bien, íntimamente conectada con ellas, la falla institucional que ha venido denunciando la mejor doctrina desde el inicio mismo de la andadura constitucional. El Senado no es una verdadera cámara de representación territorial por cuanto ni sus miembros son elegidos con ese criterio, al seguirse la circunscripción provincial en una buena parte de ellos, al igual que con las elecciones al Congreso, ni sus capacidades legislativas, presupuestarias y de control son semejantes o equiparables a las de la Cámara Baja. Respecto a la primera nota, hemos de partir de que son las Comunidades Autónomas, y no las provincias, las unidades con autonomía política y con una identidad lo suficientemente articulada ya como para servir de referencia en la adscripción de demandas ciudadanas. La delimitación provincial se debe a un modelo de Estado unitario sobrepasado y no debería ser la base de una cámara territorial que intente trasladar la voluntad de los territorios políticamente autónomos, como son las CC.AA., a la formulación del interés general del conjunto del país y de sus decisiones políticas y normativas más relevantes. Respecto al segundo "déficit" indicado, el Senado fue diseñado como cámara de segunda lectura sin apenas posibilidad de interferir verdaderamente en el procedimiento legislativo, sin poder de hacerlo de ningún modo en el presupuestario, y con muy débiles mecanismos de control del Gobierno. Es decir, el Senado apenas desempeña un papel de actor secundario y subordinado en las atribuciones principales que suelen encomendarse a los parlamentos, de ahí que su poco protagonismo y 
su débil funcionalidad no solo hayan sido denunciados por la academia, sino también por la sociedad civil y determinadas posturas políticas.

Ante la poca o nula operatividad del Senado respecto a su hipotética función territorial, no es de extrañar que el Congreso se haya progresivamente "territorializado", pues los partidos con mayor arraigo en determinadas regiones e incluso provincias, que además abanderan ser representantes de las mismas y no del conjunto de la ciudadanía, son también perfectamente conscientes de que es en el Congreso donde su voz puede tener algún efecto o consecuencia. Fenómeno este que ya no es exclusivo de los partidos nacionalistas con pretensiones centrífugas, como los vascos y catalanes 0 , en menor medidas, los gallegos y valencianos, sino que ha comenzado a extenderse a posicionamientos políticos que defienden, sin recurrir a los expedientes nacionalistas, la lucha por el territorio concreto y contra la despoblación que el mismo acusa. En este sentido Teruel Existe (TE) ha conseguido obtener un diputado en el Congreso y dos senadores en la Cámara Alta en las elecciones generales de 2019, con un programa político que hace causa tanto del histórico abandono de la provincia como de toda la España rural de la que la situación de aquella constituye quizá la máxima expresión. $Y$ es que el sistema electoral sucintamente analizado más arriba facilita la proliferación de opciones a entrar en las Cortes Generales por parte de aquellos partidos que se centren únicamente en pocas circunscripciones, o en una sola, y que consigan convencer a un número relativo de sus electores. A modo de ejemplo, el diputado de TE, Sr. Guitarte, obtuvo su acta con menos de 20.000 votos, mientras que un diputado del PSOE por Madrid (por ejemplo), tuvo que necesitar casi 100.000 apoyos.

Debido a la incapacidad estructural del bicameralismo imperfecto español de representar eficazmente a los territorios y sus necesidades y demandas singulares, incluidas muy especialmente las referidas a las diferencias interterritoriales en el ámbito socioeconómico, comienza a mutarse la naturaleza misma del Congreso de los Diputados, cuyo objeto debería ser el de representar el interés general y al conjunto de la ciudadanía en la determinación del bien común. Una posible extensión de la experiencia de TE en otras provincias y más allá de una representación anecdótica, no sólo podría aumentar la fragmentación parlamentaria y dificultar la gobernabilidad del país, sino que pondría en entredicho la finalidad misma de la representación nacional 
al perder todo atisbo de unidad y coherencia. Para evitarlo, el constitucionalismo histórico y comparado ha previsto, en el seno de los Estados compuestos y políticamente descentralizados como el nuestro, una segunda Cámara que funja como órgano de representación territorial y que, para determinadas funciones, tenga un poder equivalente al de la primera. Aquí es donde, como acabamos de ver, el modelo constitucional de 1978, con su sistema electoral a la cabeza, deja mucho que desear.

\section{III. ¿HACIA UNA CORRECCIÓN REPRESENTATIVA DEL SISTEMA DE PARTIDOS?}

La sobrerrepresentación formal de los territorios escasamente poblados o rurales no ha sido ajena a las problemáticas constitucionales contemporáneas, teniendo como ejemplo la controvertida sentencia Baker vs. Carr ya mentada. Una representatividad formal que, como hemos tenido oportunidad de indicar, no tiene por qué traducirse en una representatividad real y eficaz de los intereses de la ciudadanía de tales regiones o zonas, y máxime cuando se incumple el carácter territorial del que quiere dotarse a la cámara creada al efecto. Si el sistema de partidos lamina con su centralismo, además, las opciones de articular mecanismos eficaces de traslación de la voluntad territorial a la estatal, nos podemos llegar a encontrar con un sistema de representación que no se adecúa a los objetivos, teóricos, que deberían presidirlo y que no es funcional, en consecuencia, para la mejor formulación tanto del interés general como de las demandas territoriales a él anejas.

El rediseño de nuestro sistema de representación, y sobre todo del Senado, es una constante en toda la doctrina, cuyas primeras propuestas de reforma constitucional sobre la materia se retrotraen a los inicios mismos de la democracia actual. Una vez consolidado el sistema autonómico, o por lo menos cerrada su indefinición originaria, carece por completo de sentido la existencia de una pretendida cámara de representación territorial que no actúa como tal y que, por el contrario, se erige en un Senado de segunda lectura cuya circunscripción electoral sigue siendo la provincia y no los entes con autonomía política ya perfilada. Las desigualdades territoriales españolas, con sus diversas singularidades, deben tener cabida en la manifestación de la voluntad política eficazmente representada sin que el diseño del sistema parlamentario o 
de partidos sea obstáculo alguno. En consecuencia, lo que aquí proponemos es una reforma integral del Senado para convertirlo en una verdadera cámara de representación territorial y una reducción del sesgo centralista que acompaña a nuestra partidocracia mediante el incremento de la relación representante-representado, permitiendo, con ambas perspectivas, una mejor traslación de la preocupación por las disparidades interterritoriales.

En cuanto al diseño del Senado, la apuesta es por una composición que combine la elección directa por los ciudadanos y la indirecta por los representantes autonómicos. La protagonizada por estos últimos podría seguir exactamente el mismo esquema actual, en el que son las asambleas autonómicas las encargadas de designar a los senadores que les corresponde. Siguiendo el modelo estadounidense, y en la medida en que lo que se quiere ahora representar es al territorio concreto y su conformación política previa, lo que creemos más conveniente sería un reparto igual de senadores por designación en todas y cada una de las CC.AA. sin atender a criterios demográficos. Si se eligiera un número razonable, como 4 senadores por Comunidad, por ejemplo, tendríamos 68 designados por las asambleas legislativas autonómicas, a los que se podría añadir 1 o 2 por cada ciudad autónoma. Para que estos senadores de verdad representaran a sus territorios, y dado que la legitimidad y justificación de su existencia está en la voluntad autonómica, podrían responder en las votaciones mediante mandato imperativo de sus asambleas autonómicas de origen, como en Alemania, y votando en bloque conforme a las instrucciones recibidas. Hemos de tener en cuenta, además, que en la conformación de las asambleas autonómicas ya rige de por sí un criterio de representación territorial, sumado y corrigiendo al proporcional, de conformidad con el artículo 152.1 CE. Son muchas las CC.AA. que ya recogen en sus sistemas electorales criterios de corrección territorial ${ }^{33}$, sin llegar, eso sí, al caso vasco, quizá excesivo y sobre el que pesan no pocas dudas de constitucionalidad al quedar marginado por completo el principio de proporcionalidad $^{34}$.

\footnotetext{
${ }^{33}$ Muy interesante al respecto la perspectiva de Seijas, E. "La senda española al federalismo: garantías estatutarias del pluralismo territorial intra-autonómico (Castilla y León)", en Biglino Campos, P., y Mapelli Marchina, C. Dir., Garantías del pluralismo territorial, Madrid, CEPC, 2011, pp. 93-118.

${ }^{34}$ Trujillo, G., "El estado y las Comunidades Autónomas ante la exigencia constitucional del voto igual", Revista Española de Derecho Constitucional, № 2, 1981, pp. 9-56; p. 49.
} 
En cuanto a los elegidos por los ciudadanos, su necesidad se justifica por la potencialidad de reducir el sesgo partidocrático que pueden llegar a demostrar si se plantea a tal fin su forma de elección. Primero, la circunscripción electoral dejaría de ser la provincia para identificarse plenamente con la Comunidad Autónoma, ya que dichos senadores representarían el territorio y sus intereses, al igual que los designados por las asambleas, y tales territorios son los que ahora disfrutan de verdadera autonomía y los que, por lo tanto, pueden constituir referencias simbólicas y de adscripción política para la ciudadanía. Segundo, y para reducir el papel de los partidos nacionales y sus lógicas centralistas o aterritoriales, proponemos que se facilite al máximo la presentación de candidaturas para tales escaños, favoreciendo las agrupaciones de electores de escala autonómica y presentando siempre, como obligación, listas abiertas y desbloqueadas. El objetivo de ambas modificaciones es acercar el representante al ciudadano, y viceversa, para que la voluntad del primero y sus inquietudes (también) territoriales, puedan trasladarse con eficacia y con decisión a la Cámara Alta sin pasar necesariamente por el filtro de los grandes partidos de corte estatal. Es cierto que el desbloqueo de las listas se da ya en la elección actual al Senado, con escaso éxito, pero no lo es menos que las mismas siguen estando determinadas por las lógicas partidistas y que las elecciones se celebran para una cámara parlamentaria, recordemos, de escaso peso y trascendencia, algo que el ciudadano sabe y aprecia actuando en consecuencia, de ahí su poco interés, también, por las posibilidades que el sistema ya le brinda.

Como apuntan Renwick y Pilet, en los países europeos parece detectarse una tendencia a dotarle cada vez más relevancia y protagonismo a los candidatos en detrimento de los partidos políticos, aumentando así la personalización del proceso electoral ${ }^{35}$. Es más, en el propio sistema autonómico español se están estudiando fórmulas para desbloquear las listas en las elecciones a las asambleas legislativas, como ha estudiado María Garrote ${ }^{36}$. Asimismo, y para evitar el posicionamiento que se da actualmente en las listas para el Senado, el

\footnotetext{
${ }^{35}$ Renwick, A., y Jean-Benoit P., Faces on the Ballot. The Personalization of Electoral Systems in Europe, Oxford, Oxford University Press, 2016.

${ }^{36}$ Garrote, M., "Listas desbloqueadas en los sistemas electorales autonómicos: ¿es necesario, posible y probable?", en Pérez-Moneo M., y Vintró Castells, J., Eds., Participación política: deliberación y representación en las Comunidades Autónomas, Madrid, Congreso de los Diputados, 2017.
} 
orden de presentación de los candidatos en la papeleta, para aquellos que procedieran de los partidos políticos y no de las agrupaciones de electores, podría determinarse obligatoriamente por sorteo y no por orden alfabético. Para este tipo de senadores sí tendría que haber un criterio demográfico, puesto que su legitimidad directa deriva de la voluntad ciudadana. Por ello, se podría estudiar un sistema de reparto de senadores por cada CC.AA. en función de la población, con unos topes mínimos y máximos que garantizaran tanto la representación eficaz de todas las Comunidades como una pequeña corrección de aquellas más densamente pobladas y que provocarían, de ser exactamente proporcional el sistema seguido, una asimetría considerable. Criterios de corrección por arriba ya se siguen, por ejemplo, en las elecciones al Parlamento Europeo. Se podría incluso explorar la idea de que el número de escaños que debieran distribuirse coincidiera con los elegidos mediante designación territorial, llevando la combinación de ambas fuentes de legitimidad a la equiparación. Con esta última propuesta el Senado se compondría de alrededor 140 miembros $(70+70)$, una cifra más reducida que la actual.

El nuevo diseño que aquí planteamos tendría poca virtualidad, con todo, si no viniera acompañado de una reforma de las funciones encomendadas al Senado. Tanto para convertirlo en un órgano eficaz y útil en la persecución de su finalidad (la representación territorial), como para acercar al ciudadano a la institución y a la apertura y desbloqueo de las listas que ahora se le presentan, el Senado tendría que estar equiparado al Congreso en su relevancia en las funciones legislativa y presupuestaria en materias de especial trascendencia y vinculación con la cuestión territorial. Así, aquellas leyes que afecten directamente a la distribución de competencias entre el Estado y las CC.AA., como la determinación de los límites de la legislación básica, y aquellas otras que se refieran a la conformación presupuestaria de los Fondos de Compensación y de solidaridad interautonómica. Ahora mismo, el Senado sí se acerca tímidamente a esa equiparación en la aprobación de tales fondos en virtud del artículo 74.2 CE, pero ni aun así la Constitución consigue aquella debido a que, como ocurre en otros cauces procedimentales, finalmente la última palabra y la capacidad de desbloqueo le corresponde al Congreso de los Diputados, aunque sea esta vez por mayoría absoluta.

Para que los partidos de implantación infraestatal y con una base e ideario territoriales más consolidados terminaran volcándose en el Senado y no tanto 
en el Congreso, se podría explorar al mismo tiempo el establecimiento de barreras electorales de escala nacional que dificultaran (pero no impidieran) su presencia en una cámara pensada para la formulación del interés general del conjunto de la ciudadanía y no de los territorios en los que esta se distribuye. De ahí que la exigencia de mayor proporcionalidad y de un verdadero voto igual $^{37}$, no territorializado, tenga mucha más razón de ser para la Cámara Baja. Claro que, en nuestro caso, no debería llegarse a la radicalidad con que tal presupuesto o apriorismo es abordado en el país vecino, Portugal, que como es relativamente conocido, prohíbe en su Constitución la entrada en la Asamblea de la República de partidos regionales o locales que no sean de estricta implantación nacional (art. 51.4 CP). Ello sería inviable jurídicamente e impertinente políticamente en un país, como España, que tiene como patrimonio y riqueza no solo su diversidad nacional sino también su destacado pluralismo político, algunas de cuyas formulaciones más exitosas están íntimamente conectadas con la cuestión territorial.

Con el sistema mixto que aquí proponemos, unido al aumento del poder decisorio del Senado en su equiparación al Congreso para determinadas materias, creemos que los territorios españoles estarían mejor representados en las Cortes Generales y, por ende, que sus diversos intereses, incluidos de manera destacada los del mundo rural (mayoritario en términos territoriales), podrían ser canalizados de manera más efectiva hacia la formulación de la voluntad política estatal. Con la representación designada por las CC.AA. en igual número sin atender al criterio demográfico nos estaríamos acercando al paradigma federal $^{38}$, para el que la cámara territorial no debe seguir escrupulosamente la igualdad de voto al concederse la misma relevancia a todos los territorios por el hecho de ser sujetos políticamente autónomos y como tal reconocidos. Con la otra mitad de la representación en el Senado elegida directamente por los ciudadanos a través de listas abiertas y desbloqueadas, y donde sí primase un criterio demográfico (corregido por arriba y por abajo mediante "topes"), se podría conseguir tanto un mayor acercamiento entre los representados y los representantes fuera de la lógica provincial y de partidos, como una amortiguación del exceso de asimetría o

\footnotetext{
${ }^{37}$ Nuestro Tribunal Constitucional no tuvo ocasión de abordar la cuestión del sufragio igual hasta el año 2011, en la STC 19/2011, relativa al sistema electoral autonómico de Castilla-La Mancha.

${ }^{38}$ Urdánoz Gamuza, op. cit., p. 376.
} 
disparidad que podría imputársele al primer sistema de designación desde una óptica puramente democrática. Respecto a esta última matización no huelga recordar que las CC.AA. en España no sólo no presentan tamaños y poblaciones parecidos, sino que en determinados casos las diferencias son abismales. Compárese a modo de ejemplo, únicamente, La Rioja y la Comunidad Autónoma de Andalucía. Por ello, y aunque es cierto que tales diferencias no pesan en el clásico sistema federal estadounidense, no dejaría de ser chocante para el principio democrático la existencia de disparidades tales a igual representación, de ahí la necesidad de corregir nuevamente el parámetro.

\section{CONSIDERACIONES FINALES}

La ciencia política ha reiterado en numerosas ocasiones que existe una dificultad intrínseca en la reforma y alteración de los sistemas electorales, por cuanto quienes podrían modificarlos son precisamente los que más se benefician de su mantenimiento ${ }^{39}$. Algo que se agrava cuando, como en el caso de España, los elementos principales y definidores del sistema están constitucionalizados y, por tanto, petrificados al máximo nivel bajo el amparo de la supremacía y rigidez de la norma fundamental.

No obstante ello, desde la academia se hace siempre necesaria la formulación de hipótesis y propuestas que, diversas y en ocasiones aventuradas, puedan servir como horizonte para las reformas del mañana o abrir nuevos debates y discusiones sobre la oportunidad de modificar el funcionamiento de nuestro sistema democrático y de Derecho para adecuarlo a los nuevos retos y a los viejos dilemas. Es lo que aquí se ha pretendido, analizando en primer lugar cómo la disparidad regional socioeconómica de España, singular en su intensidad respecto a los países de su entorno, muy difícilmente puede frenarse y desviarse si, primero, los medios de redistribución de la riqueza y de intervención estatal en la economía se abandonan y, segundo, si la propia voluntad ciudadana de los territorios con autonomía es incapaz de trasladarse con efectividad a la determinación política del conjunto del país. La crisis del

\footnotetext{
${ }^{39}$ In toto, Katz, R. "Why are there so Many (or so Few) Electoral Reforms?", en M. Gallagher y P. Mitchell (eds.). The Politics of Electoral Systems, Oxford, Oxford University Press, 2005.
} 
Estado social en España, en buena medida inserta en la dinámica europea de primacía de un "constitucionalismo de mercado" 40 incompatible con el objetivo de justicia de aquella adjetivación constitucional, lastra las potencialidades interventoras de lo político sobre lo económico y social, dejados ambos ámbitos al albur de la distribución inequitativa que los intereses particulares, presididos por el afán de hiperconcentración espacial y capitalista, realizan. Las fallas iniciales de nuestro sistema autonómico, por su parte, con una Cámara de representación territorial que no hace de tal por una imposibilidad estructural debido tanto a su composición como a las funciones atribuidas, completa el camino de dificultades que ha de seguir una posible (y deseada) política que afronte el reto demográfico y las disparidades regionales.

La despoblación de una parte cada vez más extensa de nuestro territorio tiene consecuencias sumamente gravosas para la consecución de una sociedad más justa, cohesionada y respetuosa con la naturaleza. El abandono del medio rural constituye, al mismo tiempo, un desafío para la integración constitucional de una ciudadanía que se siente excluida en el disfrute de sus derechos fundamentales y de las prestaciones que los poderes públicos ofrecen. Para abordar ambos retos necesitamos rearmar nuestro Estado social con los instrumentos y mecanismos que siempre lo habían caracterizado, y si fuera necesario, desde nuevas perspectivas y con novedosos diseños ${ }^{41}$, y, por supuesto, reformar un sistema de representación que ha demostrado en estos últimos cuarenta años su autorreferencialidad partidista bajo sesgos marcadamente urbanos y favorables a la hiperconcentración de la población y los medios productivos. Aunando las dos líneas de actuación en un mismo horizonte, con propuestas fundadas y muchas veces originales (y por eso mismo, aventuradas), podremos hacer frente a la problemática de una España vacía, vacía por vaciada.

\footnotetext{
${ }^{40}$ Maestro Buelga, G., "Estado de mercado y Constitución económica: algunas reflexiones sobre la crisis constitucional europea", Revista de derecho constitucional europeo, no 8, 2007, pp. 43-73.

${ }^{41}$ Moreno González, G., "La necesaria recuperación de la constitución económica del Estado Social en España", en Martín Cubas, J., Dir., Constitución, política y administración: repensando la Constitución + cuatro décadas después, Valencia, Tirant lo Blanch, 2020, pp. 337-348.
} 